\title{
Dietary intake in adults on hemodialysis compared with guideline recommendations
}

\author{
Valeria M. Saglimbene ${ }^{1,2} \cdot$ Guobin Su$^{3,4,5} \cdot$ Germaine Wong $^{1,6} \cdot$ Patrizia Natale ${ }^{1,2} \cdot$ Marinella Ruospo $^{2}$. \\ Suetonia C. Palmer ${ }^{7}$. Jonathan C. Craig ${ }^{8}$. Juan J. Carrero ${ }^{5}$. Giovanni F. M. Strippoli ${ }^{1,2}$
}

Received: 3 September 2020 / Accepted: 29 December 2020 / Published online: 16 February 2021

(c) The Author(s) 2021

\begin{abstract}
Background Clinical practice guidelines of dietary management are designed to promote a balanced diet and maintain health in patients undergoing haemodialysis but they may not reflect patients' preferences. We aimed to investigate the consistency between the dietary intake of patients on maintenance haemodialysis and guideline recommendations.

Methods Cross-sectional analysis of the DIET-HD study, which included 6,906 adults undergoing haemodialysis in 10 European countries. Dietary intake was determined using the Global Allergy and Asthma European Network (GA ${ }^{2}$ LEN) Food Frequency Questionnaire (FFQ), and compared with the European Best Practice Guidelines. Consistency with guidelines was defined as achieving the minimum daily recommended intake for energy ( $\geq 30 \mathrm{kcal} / \mathrm{kg}$ ) and protein $(\geq 1.1 \mathrm{~g} / \mathrm{kg})$, and not exceeding the maximum recommended daily intake for phosphate $(\leq 1000 \mathrm{mg})$, potassium $(\leq 2730 \mathrm{mg})$, sodium $(\leq 2300 \mathrm{mg})$ and calcium $(\leq 800 \mathrm{mg})$.

Results Overall, patients' dietary intakes of phosphate and potassium were infrequently consistent with guidelines (consistent in $25 \%$ and $25 \%$ of patients, respectively). Almost half of the patients reported that energy (45\%) and calcium intake (53\%) was consistent with the guidelines, while the recommended intake of sodium and protein was consistent in $85 \%$ and $67 \%$ of patients, respectively. Results were similar across all participating countries. Intake was consistent with all six guideline recommendations in only $1 \%$ of patients.

Conclusion Patients on maintenance haemodialysis usually have a dietary intake which is inconsistent with current recommendations, especially for phosphate and potassium.
\end{abstract}

Keywords Diet $\cdot$ Nutrition $\cdot$ Haemodialysis $\cdot$ End-stage-kidney-disease

Giovanni F. M. Strippoli

gfmstrippoli@gmail.com

1 Faculty of Medicine and Health, Sydney School of Public Health, University of Sydney, Sydney, Australia

2 Department of Emergency and Organ Transplantation, University of Bari, Piazza Giulio Cesare, 70124 Bari, Italy

3 National Clinical Research Center for Kidney Disease, State Key Laboratory of Organ Failure Research, Department of Nephrology, Nanfang Hospital, Southern Medical University, Guangzhou City, Guangdong Province, China

4 Department of Nephrology, Guangdong Provincial Hospital of Chinese Medicine, The Second Affiliated
Hospital, Guangzhou University of Chinese Medicine, Guangzhou City, Guangdong Province, China

5 Department of Medical Epidemiology and Biostatistics, Karolinska Institutet, Stockholm, Sweden

6 Department of Renal Medicine, Westmead Hospital, Westmead, Australia

7 Department of Medicine, University of Otago Christchurch, Christchurch, New Zealand

8 College of Medicine and Public Health, Flinders University, Adelaide, Australia 


\section{Introduction}

End-stage kidney disease (ESKD) is a major public health problem affecting more than 2 million people worldwide [1]. The kidney is crucial to nutritional homeostasis. Accordingly, people with ESKD undergoing haemodialysis are advised to modify their dietary intake [2-6]. In particular, clinical practice guidelines recommend restricted phosphate, potassium and sodium intake to avoid elevated serum electrolyte levels and the associated cardiovascular complications [5, 7-13]. Concomitantly, clinical guidelines include recommendations related to sufficient energy and protein intake to avoid malnutrition [2-6]. However, consistency with these stringent recommendations is difficult because of their negative impact on quality of life. Dietary education and support strategies to promote healthy diet and adherence to dietary recommendations are also limited due to resource constraints [14, 15].

Data on dietary intake and consistency with guideline recommendations among patients undergoing haemodialysis are limited to studies with a single-centre design, small sample size and the use of heterogeneous dietary assessment methods. These limitations may preclude generalizability and comparisons across health systems [16-18]. Outside the field of nephrology there is empirical evidence to suggest that consistency with dietary recommendations in the general population or in patients with chronic diseases is associated with better outcomes [19-22].

The purpose of this study was to investigate the consistency between the dietary intake of patients on maintenance haemodialysis and guideline recommendations.

\section{Materials and methods}

\section{Study design}

This is a cross sectional sub-study of the Dietary Intake, Death and Hospitalization in Adults with ESKD Treated with Hemodialysis study (DIET-HD study), a multinational study of dietary intake in adults undergoing haemodialysis [23]. This sub-study is reported according to the Strengthening the Reporting of Observational Studies in Epidemiology (STROBE) guidelines [24].

\section{Study population}

This study includes all DIET-HD patients from the ten European countries (France, Germany, Italy, Hungary,
Poland, Portugal, Romania, Spain, Sweden and Turkey) included in the DIET-HD study.

Patients were eligible if they were adults undergoing haemodialysis for at least 90 days. Patients were excluded for significant neurocognitive disability or medical comorbidity (such as dementia) which would preclude them from understanding the Food Frequency Questionnaire (FFQ) even if assisted, life expectancy less than 6 months or a scheduled kidney transplant within 6 months. Ethics approval was obtained from all relevant institutional ethics committees and the study was conducted in accordance with the Declaration of Helsinki. All patients provided written informed consent.

\section{Baseline characteristics}

Socio-demographic, clinical and dialysis-related data were obtained from a centralized, routinely collected administrative database linked to the participant's dietary data via their unique provider identification code. All clinical sites used the same standard operating procedures to assess and record the baseline variables of interest.

\section{Dietary intake assessment}

Between January 2014 and January 2015, patients completed, during a dialysis session, the Global Allergy and Asthma European Network (GA $\left.{ }^{2} L E N\right)$ FFQ, which was designed and validated to assess the dietary intake of the past 12 months across countries using a single standardised instrument [25] (Appendix 1). We excluded patients with missing data linkage and those who completed less than $80 \%$ of the FFQ or had implausible responses (defined as a logtransformed total energy intake more than three standard deviations from the mean) (Fig. 1). Daily food intake was calculated in grams per day from standard food portion sizes as recommended by the UK's Food Standards Agency [26]. Macro- and micronutrient intake were derived using the latest available McCance \& Widdowson's Food Composition Tables [27].

\section{Dietary guidelines}

We compared the dietary intake of the study population with the recommendations from the European Best Practice Guidelines (EBPG) [5] (Table S1). These guidelines suggest the following daily target range of intake for nutrients and energy: phosphate 800 to $1000 \mathrm{mg}$, potassium 1950 to $2730 \mathrm{mg}$, sodium 2000 to $2300 \mathrm{mg}$, calcium 500 to $800 \mathrm{mg}$, protein at least $1.1 \mathrm{~g} / \mathrm{kg}$, and energy 30 to $40 \mathrm{kcal} /$ $\mathrm{kg}$. Consistency with each guideline was defined as achieving the minimum daily recommended intake for energy 


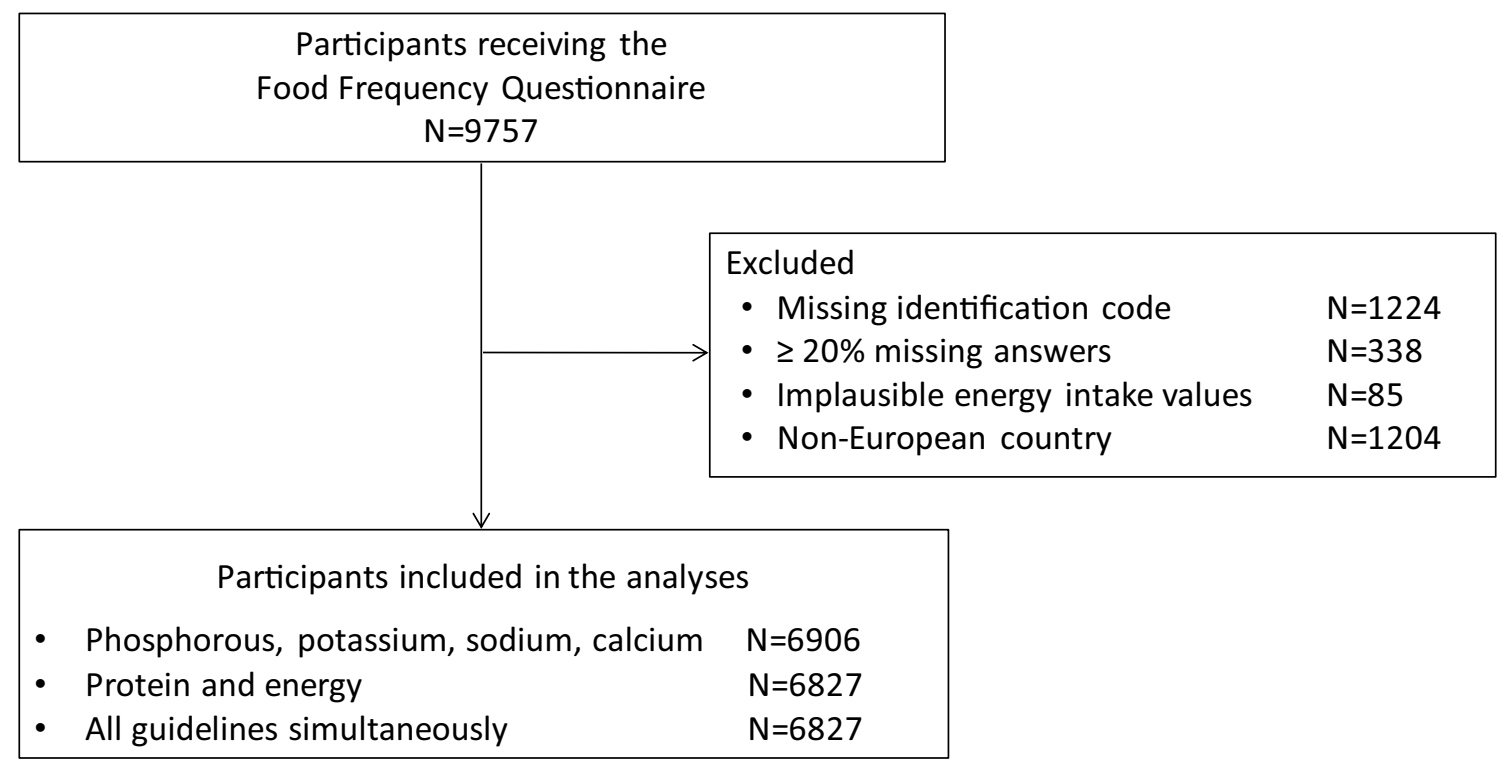

Fig. 1 Flow chart of participation

( $\geq 30 \mathrm{kcal} / \mathrm{kg}$ ) and protein $(\geq 1.1 \mathrm{~g} / \mathrm{kg})$, and not exceeding the maximum recommended daily intake, considered safe to avoid electrolyte imbalances, for phosphate $(\leq 1000 \mathrm{mg})$, potassium $(\leq 2730 \mathrm{mg})$, sodium $(\leq 2300 \mathrm{mg})$ and calcium $(\leq 800 \mathrm{mg})$. The proportion of patients with dietary intakes below, within and above each recommended target was also measured. We also evaluated how many guidelines were met simultaneously.

\section{Statistical analysis}

Baseline demographics were described and dietary intake was estimated overall and by country.

Continuous variables were summarized as mean and standard deviation or median and interquartile range according to their distribution. Categorical variables were summarized as frequencies and proportions. Estimated food (servings per day), energy (kcal) and nutrient (grams per day) intake was analysed as continuous variables and expressed as median and interquartile range. Consistency with each dietary guideline was analysed as a dichotomous variable (achieving or not achieving the minimum daily recommended intake for energy and protein; exceeding or not exceeding the maximum recommended daily intake for phosphate, potassium, sodium and calcium) and a three level variable (below, within and above each target range) and summarized using frequencies and proportions. Analysis of consistency with each dietary guideline included patients with complete data for the guideline of interest. Results were expressed as adjusted odds ratios (OR) and their 95\% confidence interval (CI). Analyses were performed in SAS version 9.3 (SAS Institute, Cary, NC).

\section{Results}

Nine thousand seven hundred fifty-seven patients treated with haemodialysis participated in the DIET-HD study. Of these, 6906 (71\%) were included in this analysis after exclusion of patients from non-European countries (Argentina) (1204), and those with missing data linkage (1224) or insufficient (338) or implausible (85) FFQ responses (Fig. 1).

The mean age of the study population was 64.4 (standard deviation 14.5 ) years old, $58 \%$ were men, $34 \%$ were current or former smokers, $16 \%$ engaged in daily physical activity, $86 \%$ had reported hypertension, 33\% had diabetes, $13 \%$ had a prior myocardial infarction, and $9 \%$ had a prior history of stroke (Table 1, Table S2).

\section{Dietary intake}

The median (interquartile range) servings per day of the main food groups were: fruits 2.6 (1.5-4.6), vegetables 3.8 (2.2-6.1), legumes and nuts $0.4(0.1-0.6)$, cereals 2.4 (1.3-3.4), dairy $1.4(0.7-2.4)$, fish and white meat 0.7 (0.4-1.3), and red meat and meat products 1.1 (0.6 to 1.9). The median daily intake of energy and protein per $\mathrm{kg}$ of dry body weight was 28.4 (20.5-38.9) and 1.4 (0.98-1.98), respectively. The median daily intake of minerals was calcium 774 (541-1095) mg, phosphate 1,438 (999-2,047) $\mathrm{mg}$, potassium $3,655(2,625-5,191) \mathrm{mg}$ and sodium 1337 (929-1907) mg (Table 2). Dietary intake is reported separately by gender in Table S3. 
Table 1 Baseline characteristics of patients

\begin{tabular}{|c|c|c|}
\hline Characteristics & $\mathrm{N}$ with available data & $\begin{array}{l}\text { Mean (SD) or } \\
\text { number }(\%)\end{array}$ \\
\hline Age (years) & 6906 & \\
\hline Mean (SD) & & $64.4(14.5)$ \\
\hline$<65, n(\%)$ & & $3257(47)$ \\
\hline$\geq 60, n(\%)$ & & $3649(53)$ \\
\hline Male, $n(\%)$ & 6906 & $4011(58)$ \\
\hline Country, $n(\%)$ & 6906 & \\
\hline France & & $221(3)$ \\
\hline Germany & & $178(3)$ \\
\hline Hungary & & $554(8)$ \\
\hline Italy & & $543(8)$ \\
\hline Poland & & $434(6)$ \\
\hline Portugal & & $1777(26)$ \\
\hline Romania & & $1000(14)$ \\
\hline Spain & & $1041(15)$ \\
\hline Sweden & & $51(1)$ \\
\hline Turkey & & $1107(16)$ \\
\hline Current or former smoker, $n(\%)$ & 5688 & $1918(34)$ \\
\hline Married/Life partner, $n(\%)$ & 5264 & $3640(69)$ \\
\hline Secondary education or higher, $n(\%)$ & 5506 & $2524(46)$ \\
\hline Daily physical activity (self-reported), $n(\%)$ & 5613 & $917(16)$ \\
\hline Body mass index, $\mathrm{kg} / \mathrm{m}^{2}$ (mean, $\mathrm{SD}$ ) & 6701 & \\
\hline Underweight $(<18.5), n(\%)$ & & $311(5)$ \\
\hline Normal range (18.5-24.9), $n(\%)$ & & $2816(42)$ \\
\hline Pre-obese (25.0-29.9), $n(\%)$ & & $2286(34)$ \\
\hline Obese ( $\geq 30.0), n(\%)$ & & $1288(19)$ \\
\hline Hypertension, $n(\%)$ & 6145 & $5920(86)$ \\
\hline Diabetes Mellitus, $n(\%)$ & 6110 & $1987(33)$ \\
\hline Congestive heart failure, $n(\%)$ & 6099 & $1195(20)$ \\
\hline Myocardial infarction, $n(\%)$ & 6065 & $795(13)$ \\
\hline Stroke, $n(\%)$ & 6058 & $572(9)$ \\
\hline
\end{tabular}

$S D$ standard deviation

\section{Consistency with guideline recommendations}

Respectively, 1731 (25\%) and 1914 (28\%) patients did not exceed the maximum dietary recommended levels of phosphate $(\leq 1000 \mathrm{mg})$ and potassium $(\leq 2730 \mathrm{mg})$. Dietary intake was consistent with recommended daily energy $(\geq 30 \mathrm{kcal} / \mathrm{kg}, 3084$ [45\%]) and calcium $(\leq 800 \mathrm{mg} /$ day, 3654 [53\%]) intake in about half of patients, while the sodium $(\leq 2300 \mathrm{mg} /$ day $)$ and protein intake $(\geq 1.1 \mathrm{~g} / \mathrm{kg})$ was consistent with guidelines in $5848(85 \%)$ and 4598 (67\%) of patients, respectively (Fig. 2). The proportion of patients achieving the specific target ranges was very low (Figure S1). Of 6827 patients with available data for the assessment of consistency with all six guideline recommendations simultaneously, $22(0 \%)$ had dietary intakes consistent with zero recommendations, 308 (5\%) one,
1731 (25\%) two, 2521 (37\%) three, 1909 (28\%) four, 288 (4\%) five, and 48 (1\%) had intake consistent with all six recommendations (Fig. 3).

There was little variation in the consistency with ERPB for sodium (from $62 \%$ in Hungary to $92 \%$ in Italy) intake among countries, and a larger variation for energy (from $25 \%$ in Germany to $53 \%$ in France), protein (from $36 \%$ in Germany up to $76 \%$ in Portugal), potassium (from $16 \%$ in Romania up to in 54\% Germany), calcium (from 36\% in Hungary up to $65 \%$ in Poland), and phosphorus (from $6 \%$ in Sweden up to $39 \%$ in Germany). Overall, the consistency with dietary guidelines varied across countries but followed a similar pattern with lower consistency with phosphate, potassium, energy and calcium and higher consistency with protein and sodium guidelines (Fig. 4, Figure S2, Table S3). 
Table 2 Daily food, energy, and nutrient intake

\begin{tabular}{ll}
\hline Dietary intake & Median (interquartile range) \\
\hline Foods (servings/day) & \\
Fruit & $2.6(1.5-4.6)$ \\
Vegetables & $3.8(2.2-6.1)$ \\
Legumes and nuts & $0.4(0.1-0.6)$ \\
Cereals & $2.4(1.3-3.4)$ \\
Dairy & $1.4(0.7-2.4)$ \\
Fish and white meat & $0.7(0.4-1.3)$ \\
Red meat and meat products & $1.1(0.6-1.9)$ \\
Sweets and sweetened drinks & $2.4(1.1-3.9)$ \\
Energy (kcal/day) & $1937(14,450-2568)$ \\
Macronutrients (g/day) & \\
Carbohydrate & $215(154-295)$ \\
Protein & $96(68-131)$ \\
Total fat & $75(54-104)$ \\
Saturated fat & $24(16-34)$ \\
Fibre & $12(8-18)$ \\
Total sugar & $105(68-163)$ \\
Alcohol & $0.7(0.1-4.7)$ \\
Micronutrients (mg/day) & \\
Calcium & $774(541-10,952)$ \\
Phosphate & $1438(999-2047)$ \\
Potassium & $3655(2625-5191)$ \\
Sodium & $1337(929-1907)$ \\
\hline
\end{tabular}

$N=6903$ for fruit, 6905 for vegetables, 6904 for cereals and 6906 for all others

\section{Discussion}

In this study involving 6906 patients undergoing haemodialysis in 10 European countries, the consistency between the reported dietary intake and clinical practice guideline recommendations was generally low. In particular, a high proportion of the study population had dietary intake of phosphate and potassium that exceeded recommendations. In half of the patients, dietary composition exceeded the maximum recommended intake of calcium, while sodium restriction was consistent with guidelines for most patients. Almost 50 and $70 \%$ of patients appeared to have dietary total energy and protein content that was consistent with the minimum recommended intake. As expected, the overall consistency was much lower when measured as achieving specific nutrient target ranges (compared with not exceeding the maximum recommended intake or achieving the minimum recommended intake). Consistency with dietary guidelines followed a similar pattern across participating countries. The overall consistency of dietary composition with six renal dietary recommendations occurred in approximately $1 \%$ of patients.
Although comparing the dietary intake across different studies is challenging given the variety in study populations and measurement methods used, our finding of generally low consistency of dietary intake with dietary practice guidelines among the haemodialysis population is consistent with previous evidence [16-18, 28, 29] and may be explained by the following. First, the "renal diet" is one of the most difficult-to-attain diets, with a strong focus on nutrients rather than food intake, and strategically difficult to implement in real-life settings [30]. The renal food menus are extremely restrictive, dull, and not enticing. Strict adherence to these diets is known to have a direct negative impact on the overall quality of life of patients on dialysis. Patients report frustration in tracking nutrients, and a perception that 'there is nothing left to eat' if they followed the very stringent dietary instructions [15]. Second, the dietary guideline recommendations in haemodialysis are complex, extremely difficult to follow and may require on-going education and guidance from health professionals to achieve consistency of dietary intake. For instance, the most common and simplistic belief for restricting potassium is reducing fruit and vegetable intake. However, potassium is also present in similar amounts in some animal products such as meat and poultry, and in food additives [31]. Cooking methods also play an important role and the combination in which foods are eaten does as well. Boiling reduces the natural potassium content of foods [32], and net potassium absorption in the gut depends on concomitant intake of alkali and fibre [31, 33-35]. In view of the scope and complexity of the renal diet parameters, few nutritional, educational and clinical strategies have shown to be effective in the dialysis and CKD populations [36]. Patients have expressed dissatisfaction with the information they received from health care providers, a great deal of which is unclear or inconsistent $[37,38]$ and not individualized. Patients are often left unsupported and feel disconnected with their healthcare providers $[14,39,40]$. Third, the evidence that underpins these recommendations is reliant on observational studies and expert opinions without consumer engagement in the guideline development process. Therefore, patients may lack trust in the actual benefits of dietary recommendations and have identified the evaluation of dietary restrictions on health outcomes, including quality of life, as a research priority [41, 42].

Notably, consistency with salt restrictions appeared higher than with recommendations for other nutrients. This could be due to an underestimation of the salt intake as measured by the FFQ or to the large educational campaign in the general population in Europe about the effects of sodium on blood pressure that, after being carried out for several years, may have reached its goal. If this is true, long term educational strategies for other nutrients, such as potassium or phosphorus, could be effective over time in this specific population. 
A

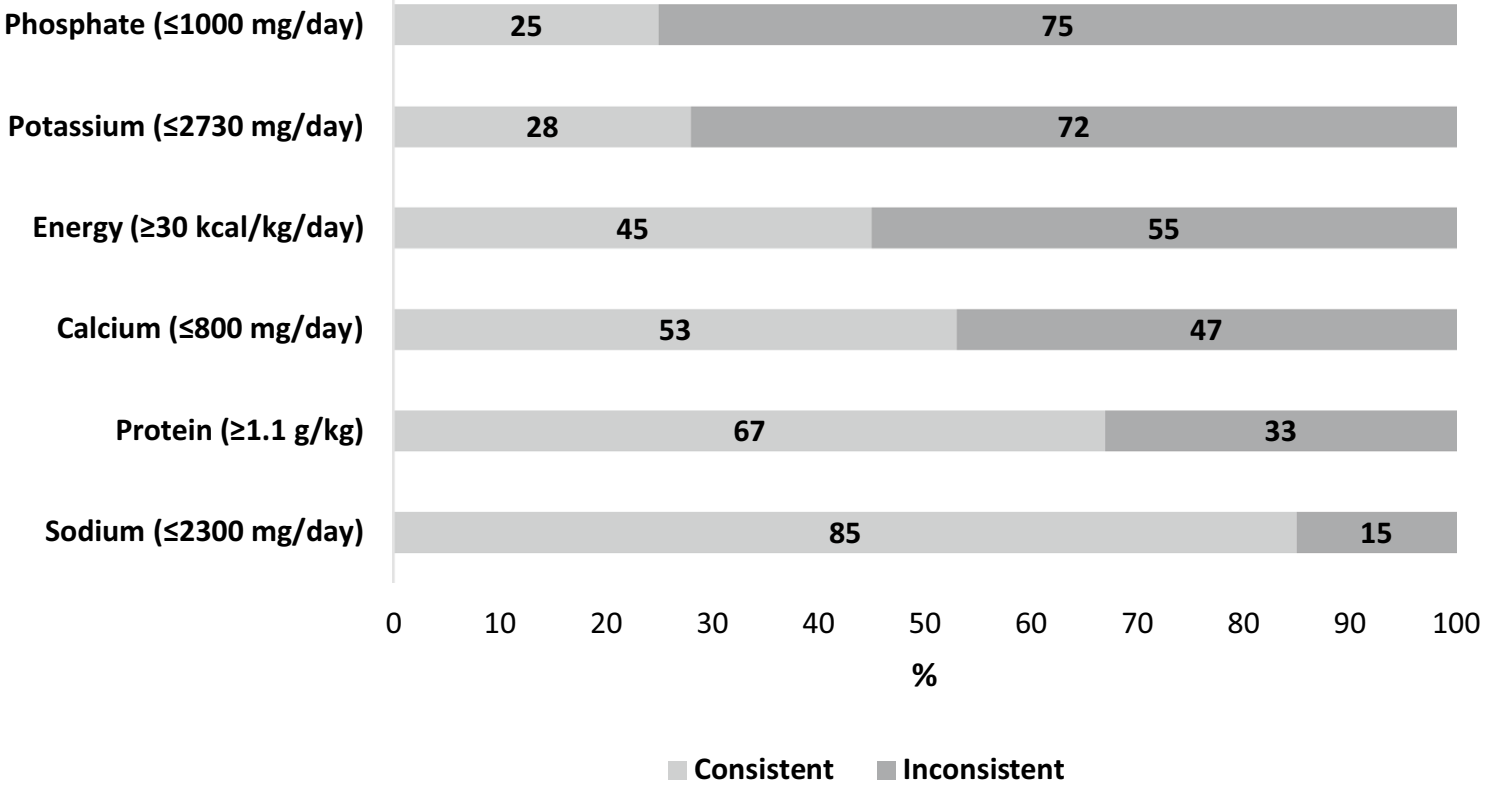

B

Phosphate (800-1000 mg/day)

14

11

75

Potassium (1950-2730 mg/day)

12

16

72

Energy (30-40 kcal/kg/day)

55

22

23

Calcium (500-800 mg/day)

21

32

47

Protein $(\geq 1.1 \mathrm{~g} / \mathrm{kg})$

33

33

67

Sodium (2000-2300 mg/day)

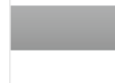

0

$10 \quad 20$

$30 \quad 40$

$\begin{array}{lll}50 & 60 & 70\end{array}$

$80 \quad 90$

100

Below the range $\square$ Within range $\square$ Above the range

$\mathrm{N}=6827$ for energy and protein; $\mathrm{N}=6906$ for the remaining recommendations

Fig. 2 a Proportion of patients reporting dietary intake consistent with guidelines (achieving the minimum intake for energy and protein, and not exceeding the maximum intake for phosphate, potassium, sodium and calcium). b Proportion of patients reporting dietary

The present study has considerable strengths including the large sample size, the multinational setting and the use of a common dietary assessment method which allowed comparisons of consistency with clinical practice guidelines among European countries. This study also has intake below, within and above the recommend range of nutrients and energy intake. $N=6827$ for energy and protein; $N=6906$ for the remaining recommendations

potential limitations. The dietary intake was self-reported and based on one single measurement. The study relied on a FFQ, which used standard food portion sizes and has been validated against plasma phospholipid fatty acids, but not with other dietary assessment methods, nor in the setting 
Fig. 3 Proportion of patients reporting dietary intake consistent with multiple guideline recommendations $(N=6827)$. The figure shows the percentage of patients that met one or more of the following recommendations: Energy: $\geq 30 \mathrm{kcal} /$ $\mathrm{kg} /$ day; Protein: $\geq 1.1 \mathrm{~g} / \mathrm{kg} /$ day; Phosphate: $\leq 1000 \mathrm{mg} /$ day; Potassium: $\leq 2730 \mathrm{mg} /$ day; Sodium: $\leq 2300 \mathrm{mg} /$ day; Calcium: $\leq 800 \mathrm{mg} /$ day

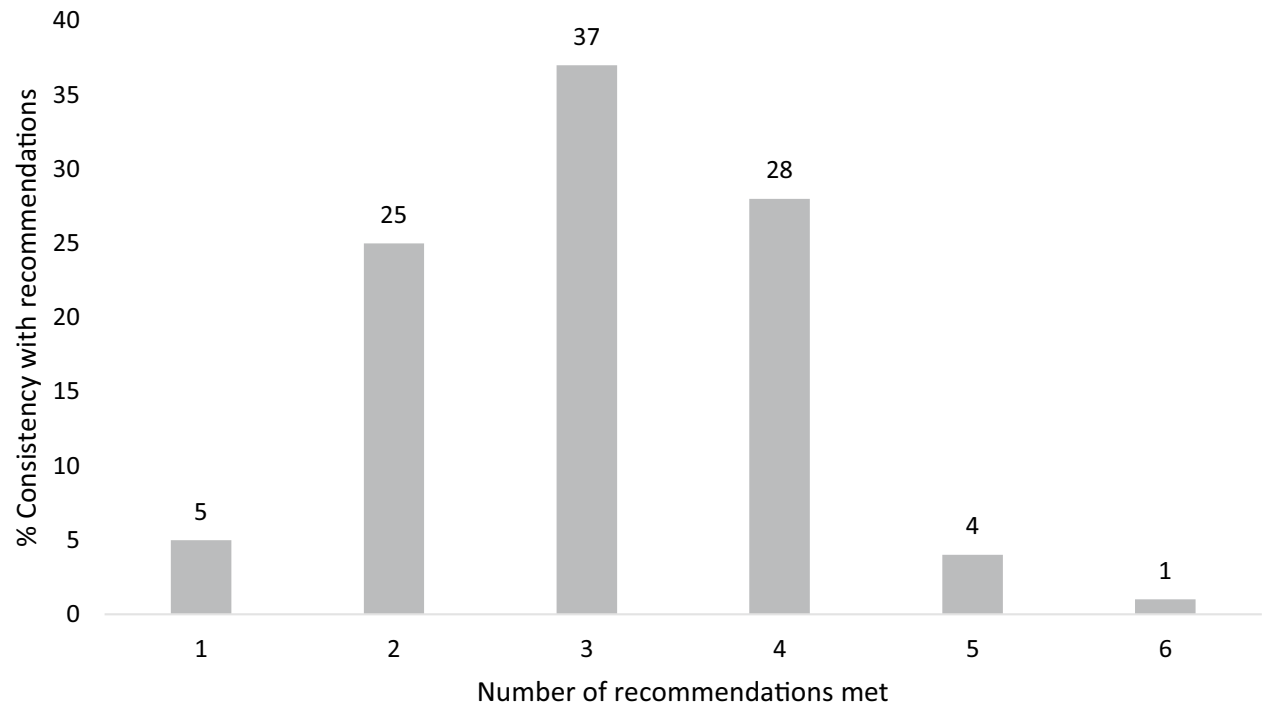

100

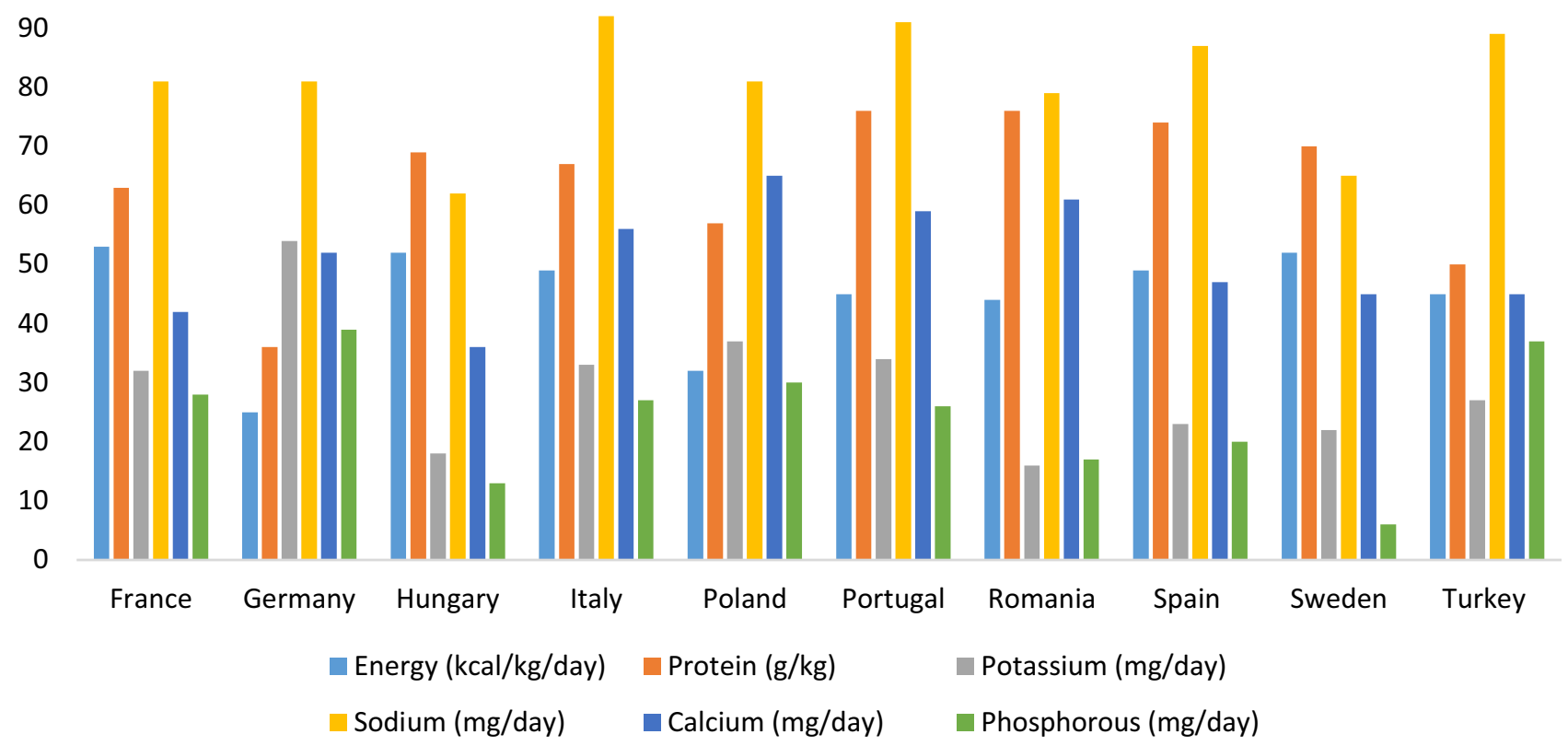

Fig. 4 Proportion of patients reporting dietary intake consistent with European Best Practice Guidelines recommendations, by country. The figure shows the percentage of patients that met one or more of the following recommendations: Energy: $\geq 30 \mathrm{kcal} / \mathrm{kg} /$

of haemodialysis. Collectively, these limitations may have led to measurement errors and inaccurate absolute dietary intakes. In addition, FFQs may not be sensitive to account for nutrient loss through cooking methods or for the intake of food additives and condiments. This may have resulted in an underestimated intake of nutrients such as phosphate and sodium, and therefore in an increased observed percentage of intake within the safe thresholds. We could only evaluate day; Protein: $\geq 1.1 \mathrm{~g} / \mathrm{kg} / \mathrm{day} ;$ Phosphate: $\leq 1000 \mathrm{mg} / \mathrm{day} ;$ Potassium: $\leq 2730 \mathrm{mg} /$ day; Sodium: $\leq 2300 \mathrm{mg} /$ day; Calcium: $\leq 800 \mathrm{mg} /$ day

consistency with dietary guidelines in patients who provided sufficient responses to the FFQ, and extrapolation of results to other dialysis patients should be done with caution. Finally, data on how many centres had a dietary education program or referred patients to dieticians for a structured approach were not available.

These findings of frequently low consistency of dietary content with nutritional recommendations, together with 
documented lower quality of life with dietary restrictions and the uncertain benefits of single nutrient restrictions $[30,43]$ suggest that additional evaluation of the evidentiary basis for dietary modification in haemodialysis is warranted. Such an approach is aligned with key research priorities identified by consumers and stakeholders [41, 42]. Our findings of very low consistency with recommendations when evaluating specific nutrient target ranges suggest that dietary guidelines consisting in narrow recommended nutrient levels might not be practical or feasible in real-life settings in which there is no purposive interventional or educational program in the study. Evaluation of whole dietary patterns may be easier due to the lower consistency we see with individual components of dietary content. Besides, the guideline only gives a recommended range of specific values for some nutrients for reference while it should be tailored according to the individual conditions. For instance, in patients with normokalemia and/ or good residual renal function, low potassium intake may not be strictly necessary. Of note, the recommended range of specific values in the EBPG is generally consistent with the newly published Kidney Disease Outcome Quality Initiatives (KDOQI) guidelines [44]. It might be interesting to further investigate whether adherence to guidelines is associated with better outcomes in this population.

In conclusion, the dietary intake of patients on haemodialysis is usually inconsistent with guideline recommendations, particularly for recommended levels of phosphate, potassium, calcium and energy intake. Strategies to increase consistency should be evaluated also to support investigations of the impact of dietary recommendations on clinical outcomes and health-related quality of life.

Supplementary Information The online version contains supplementary material available at https://doi.org/10.1007/s40620-020-00962-3.

Acknowledgements G.S is supported by the European Renal Association-European Dialysis Transplant Association Young Fellowship Programme, Karolinska Institutet Research Grant (No. 202001616), partly supported by the Science and Technology Research Fund from Guangdong provincial hospital of Chinese medicine, China (No. YN2018QL08), National Nature Science Foundation of China (No. 82004205), China Postdoctoral Science Foundation (Nos. 2020M672741; 2020TQ0137). The funding source was not involved in design and conduct of the study; collection, management, analysis, and interpretation of the data; preparation, review, or approval of the manuscript; and decision to submit the manuscript for publication. We acknowledge the Global Asthma and Allergy Network of Excellence $\left(G^{2} L E N\right)$ for facilitating the use of the GA ${ }^{2} L E N$ FFQ and the list of clinicians and health care professionals at the participating centres (Appendix 2).

Author contributions Conception and design: VS, GW, JCC, JJC, GFMS. Data acquisition: VS, PN, MR, GFMS. Data analysis: VS, GS, PN. Data interpretation: All authors. Drafting of the manuscript: VS, GS, JJC. All authors approved the final version of the manuscript: All authors.
Funding Open Access funding provided by Karolinska Institute.

\section{Compliance with ethical standards}

\section{Conflict of interest None.}

Ethics approval Ethics approval was obtained from all relevant institutional ethics committees. All procedures performed in studies involving human participants were in accordance with the ethical standards of the institutional and/or national research committees and with the 1964 Helsinki Declaration and its later amendments or comparable ethical standards.

Consent to participate All patients provided written informed consent.

Open Access This article is licensed under a Creative Commons Attribution 4.0 International License, which permits use, sharing, adaptation, distribution and reproduction in any medium or format, as long as you give appropriate credit to the original author(s) and the source, provide a link to the Creative Commons licence, and indicate if changes were made. The images or other third party material in this article are included in the article's Creative Commons licence, unless indicated otherwise in a credit line to the material. If material is not included in the article's Creative Commons licence and your intended use is not permitted by statutory regulation or exceeds the permitted use, you will need to obtain permission directly from the copyright holder. To view a copy of this licence, visit http://creativecommons.org/licenses/by/4.0/.

\section{References}

1. 1Hill NR, F. S., Oke JL, Hirst JA, O'Callaghan CA, Lasserson1 DS, Hobbs FDR (2016) Global prevalence of chronic kidney disease - a systematic review and meta-analysis. PLos One 11, e 0158765

2. Daugirdas JT et al (2015) Kdoqi clinical practice guideline for hemodialysis adequacy: 2015 update. Am J Kidney Dis 66:884-930

3. National Kidney Foundation Dialysis Outcomes Quality Initiative (2010) Nutrition and hemodialysis. https://www.kidney.org/nutri tion/Dialysis

4. Cano NJM et al (2009) ESPEN guidelines on parenteral nutrition: adult renal failure. Clin Nutr 28:401-414. https://doi. org/10.1016/j.clnu.2009.05.016

5. 5Fouque D et al (2007) EBPG guideline on nutrition. Nephrol Dial Transplant 22 Suppl 2, ii45-87, https://doi.org/10.1093/ndt/ gfm020

6. 6EDTNA/ERCA (2002) D. S. I. G. o. t. European guidelines for the nutritional care of adult renal patients

7. Carrero JJ et al (2013) Etiology of the protein-energy wasting syndrome in chronic kidney disease: a consensus statement from the international society of renal nutrition and metabolism (ISRNM). J Renal Nutr 23:77-90. https://doi.org/10.1053/j.jrn.2013.01.001

8. Cupisti A et al (2018) Nutritional treatment of advanced CKD: twenty consensus statements. J Nephrol 31:457-473. https://doi. org/10.1007/s40620-018-0497-z

9. Kovesdy CP et al (2017) Potassium homeostasis in health and disease: a scientific workshop cosponsored by the National Kidney Foundation and the American Society of Hypertension. Am J Kidney Dis 70:844-858. https://doi.org/10.1053/j.ajkd.2017.09.003

10. Dasgupta I, Shroff R, Bennett-Jones D, McVeigh G (2013) Management of hyperphosphataemia in chronic kidney disease: 
summary of National Institute for Health and Clinical Excellence (NICE) guideline. Nephron Clin Pract 124:1-9. https://doi. org/10.1159/000354711

11. Dhingra R et al (2007) Relations of serum phosphorus and calcium levels to the incidence of cardiovascular disease in the community. Arch Intern Med 167:879-885. https://doi.org/10.1001/ archinte.167.9.879

12. Kalantar-Zadeh K et al (2006) Survival predictability of timevarying indicators of bone disease in maintenance hemodialysis patients. Kidney Int 70:771-780. https://doi.org/10.1038/ sj.ki.5001514

13. Kalantar-Zadeh K et al (2009) Fluid retention is associated with cardiovascular mortality in patients undergoing long-term hemodialysis. Circulation 119:671-679

14. Hand RK, Burrowes JD (2015) Renal Dietitians' perceptions of roles and responsibilities in outpatient dialysis facilities. J Ren Nutr 25:404-411. https://doi.org/10.1053/j.jrn.2015.04.008

15. St-Jules DE, Woolf K, Pompeii ML, Sevick MA (2016) Exploring problems in following the hemodialysis diet and their relation to energy and nutrient intakes: the balancewise study. J Renal Nutr 26:118-124

16. Bossola MDSE, Viola A, Leo A, Carlomagno G, Monteburini T, Cenerelli S, Santarelli S, Boggi R, Miggiano G, Vulpio C, Mele C, Tazza L (2014) Dietary intake of trace elements, minerals, and vitamins of patients on chronic hemodialysis. Int Urol Nephrol 46:809-815. https://doi.org/10.1007/s11255-014-0689-y

17. Lambert K, Mullan J, Mansfield K (2017) An integrative review of the methodology and findings regarding dietary adherence in end stage kidney disease. BMC Nephrol. https://doi.org/10.1186/ s12882-017-0734-z

18. Luis D et al (2016) Dietary quality and adherence to dietary recommendations in patients undergoing hemodialysis. J Ren Nutr 26:190-195. https://doi.org/10.1053/j.jrn.2015.11.004

19. Voortman $\mathrm{T}$ et al (2017) Adherence to the 2015 Dutch dietary guidelines and risk of non-communicable diseases and mortality in the Rotterdam Study. Eur J Epidemiol 32:993-1005. https://doi. org/10.1007/s10654-017-0295-2

20. Jankovic $\mathbf{N}$ et al (2014) Adherence to a healthy diet according to the World Health Organization guidelines and all-cause mortality in elderly adults from Europe and the United States. Am J Epidemiol 180:978-988. https://doi.org/10.1093/aje/kwu229

21. Desroches $S$ et al (2013) Interventions to enhance adherence to dietary advice for preventing and managing chronic diseases in adults. Cochrane Database Syst Rev. https://doi. org/10.1002/14651858.CD008722.pub2

22. Saran R et al (2003) Nonadherence in hemodialysis: associations with mortality, hospitalization, and practice patterns in the DOPPS. Kidney Int 64:254-262. https://doi.org/10.104 6/j.1523-1755.2003.00064.x

23. Palmer SCRM, Campbell KL, Garcia Larsen V, Saglimbene V, Natale P et al (2015) Nutrition and dietary intake and their association with mortality and hospitalisation in adults with chronic kidney disease treated with haemodialysis: protocol for DIET-HD, a prospective multinational cohort study. BMJ Open 5:e006897

24. von Elm EAD, Egger M, Pocock SJ, Gotzsche PC, Vandenbroucke JP (2008) The Strengthening the Reporting of Observational Studies in Epidemiology (STROBE) statement. J Clin Epidemiol 61:344-349

25. Garcia-Larsen $\mathrm{V}$ et al (2011) Use of a common food frequency questionnaire (FFQ) to assess dietary patterns and their relation to allergy and asthma in Europe: pilot study of the GA2LEN FFQ. Eur J Clin Nutr 65:750-756. https://doi.org/10.1038/ejcn.2011.15

26. 26Food Standards Agency (1994) Food Portion Sizes (Maff Handbook). Available at: https://www.amazon.co.uk/Food-Porti on-Sizes-Maff-Handbook/dp/0112429610
27. Chandy SJ et al (2014) High cost burden and health consequences of antibiotic resistance: the price to pay. J Infect Dev Countries 8:1096-1102. https://doi.org/10.3855/jidc.4745

28. Kalantar-Zadeh K, Kopple JD, Deepak S, Block D, Block G (2002) Food intake characteristics of hemodialysis patients as obtained by food frequency questionnaire. J Ren Nutr 12:17-31. https://doi.org/10.1053/jren.2002.29598

29. Khoueiry $\mathrm{G}$ et al (2011) Dietary intake in hemodialysis patients does not reflect a heart healthy diet. J Ren Nutr 21:438-447. https ://doi.org/10.1053/j.jrn.2010.09.001

30. Biruete A, Jeong JH, Barnes JL, Wilund KR (2017) Modified nutritional recommendations to improve dietary patterns and outcomes in hemodialysis patients. J Ren Nutr 27:62-70. https://doi. org/10.1053/j.jrn.2016.06.001

31. St-Jules DE, Goldfarb DS, Sevick MA (2016) Nutrient non-equivalence: does restricting high-potassium plant foods help to prevent hyperkalemia in hemodialysis patients? J Renal Nutr 26:282-287. https://doi.org/10.1053/j.jrn.2016.02.005

32. D'Alessandro C et al (2016) "Dietaly": practical issues for the nutritional management of CKD patients in Italy. BMC nephrology 17:102. https://doi.org/10.1186/s12882-016-0296-5

33. Palmer SC et al (2015) Dietary and fluid restrictions in CKD: a thematic synthesis of patient views from qualitative studies. Am J Kidney Dis 65:559-573

34. Carlisle EJ et al (1991) Modulation of the secretion of potassium by accompanying anions in humans. Kidney Int 39:1206-1212. https://doi.org/10.1038/ki.1991.152

35. Cupisti A, Kovesdy CP, D’Alessandro C, Kalantar-Zadeh K (2018) Dietary approach to recurrent or chronic hyperkalaemia in patients with decreased kidney function. Nutrients. https://doi. org/10.3390/nu10030261

36. Goraya N, Simoni J, Jo CH, Wesson DE (2014) Treatment of metabolic acidosis in patients with stage 3 chronic kidney disease with fruits and vegetables or oral bicarbonate reduces urine angiotensinogen and preserves glomerular filtration rate. Kidney Int 86:1031-1038. https://doi.org/10.1038/ki.2014.83

37. Bonner A, Lloyd A (2012) Exploring the information practices of people with end-stage kidney disease. J Ren Care 38:124-130. https://doi.org/10.1111/j.1755-6686.2012.00258.x

38. Tong A et al (2009) Patients' experiences and perspectives of living with CKD. Am J Kidney Dis 53:689-700. https://doi. org/10.1053/j.ajkd.2008.10.050

39. Tsai WC et al (2016) Additional benefit of dietitian involvement in dialysis staffs-led diet education on uncontrolled hyperphosphatemia in hemodialysis patients. Clin Exp Nephrol 20:815-821. https://doi.org/10.1007/s10157-015-1212-1

40. Ikizler TA, Franch HA, Kalantar-Zadeh K, ter Wee PM, Wanner C (2014) Time to revisit the role of renal dietitian in the dialysis unit. J Ren Nutr 24:58-60. https://doi.org/10.1053/j.jrn.2013.10.006

41. Tong A et al (2015) Research priorities in CKD: report of a national workshop conducted in Australia. Am J Kidney Dis 66:212-222. https://doi.org/10.1053/j.ajkd.2015.02.341

42. Manns B et al (2014) Setting research priorities for patients on or nearing dialysis. Clin J Am Soc Nephrol 9:1813-1821. https:// doi.org/10.2215/CJN.01610214

43. Kalantar-Zadeh $\mathrm{K}$ et al (2015) Dietary restrictions in dialysis patients: is there anything left to eat? Semin Dial 28:159-168

44. Ikizler TA et al (2020) KDOQI Clinical Practice Guideline for Nutrition in CKD: 2020 Update. Am J Kidney Dis 76:S1-S107. https://doi.org/10.1053/j.ajkd.2020.05.006

Publisher's Note Springer Nature remains neutral with regard to jurisdictional claims in published maps and institutional affiliations. 